\title{
Pumice as Biological Carriers Improve Impact Load Resistance of UASB Reactors During the Treatment of Raw Incineration Leachates
}

\author{
Yong Zhang,2*, Qunlin Hu', Tao Wang ${ }^{1}$, Zhen Jin ${ }^{3}$, Tao Luo ${ }^{1,2}$, Jian Huang ${ }^{1}$, \\ Guangsong Xu' ${ }^{1}$, Yu Zhan', Hui Wang ${ }^{1}$ \\ ${ }^{1}$ School of Environment and Energy Engineering, Anhui Jianzhu University, Hefei, 230601, China \\ ${ }^{2}$ Anhui Provincial Key Laboratory of Environment Pollution Control and Resource Reuse, Hefei, 230601, China \\ ${ }^{3}$ School of Materials and Chemical Engineering, Anhui Jianzhu University, Hefei, 230601, China
}

Received: 27 April 2021

Accepted: 21 October 2021

\begin{abstract}
In the present research, the effects of pumice on impact load resistance and microbial community structure in anaerobic granular sludge of up-flow anaerobic sludge bed reactors (UASB) were studied. Our results indicated that the addition of pumice was able to promote the degradation of organic matter, reduce the start-up time, and improve the impact load resistance of the UASB reactor. Compared with the control, the start-up time of the UASB reactor was reduced by 12 days. When the organic load gradually increased from $9.84 \mathrm{~kg} \mathrm{COD} /\left(\mathrm{m}^{3} \cdot \mathrm{d}\right)$ to $33.28 \mathrm{~kg} \mathrm{COD} /\left(\mathrm{m}^{3} \cdot \mathrm{d}\right)$, the average COD removal rate in the reactor containing pumices increased by $10.53 \%$ as compared to control. High-throughput sequencing showed that the addition of pumices provided a favorable environment for microbial aggregation, and increased the richness and diversity of microorganisms in the granular sludge. The community structure of methanogens indicated that, in the presence of pumices and under the impact of organic load, the dominant methanogens were Methanosaeta instead of Methanbacterium.
\end{abstract}

Keywords: pumice, impact resistance, microbial community structure, UASB

\section{Introduction}

Leachate produced in municipal solid waste (MSW) incineration is a kind of complex and highly concentrated fluid. It generates in the garbage storage pit stacking step during the anaerobic acidification of the organic components present in the MSW [1].

*e-mail: 1973721092@qq.com
Landfill leachate usually contains a wide variety of organic pollutants, as well as high concentrations of salts, heavy metals, ammonia nitrogen, and total nitrogen. In different places, the leachate varies greatly due to the diversity of garbage components. The improper treatment of leachate would largely pollute the environment. Therefore, developing a suitable treatment method during leachate is still a big challenge [2].

UASB reactor is an effective treatment method for waste incineration generated leachate. Recently, many studies have been focused on the UASB reactor based 
leachate treatment [3]. However, some aspects limit the practical application of UASB reactors, such as low anti-impact load and long starting time [4]. Thus, in order to improve the treatment efficient of the UASB reactor on leachate, it is an urgent need to improve anti-impact load performance and shorten the start-up time of UASB reactors, in order to provide proper and efficient leachate treatments.

In order to solve those problems, a lot of studies have been conducted on improving the reactor stability and shortening the starting time. Former reports have indicated that nucleation carriers can effectively improve the performance of UASB reactors. These carriers can accelerate the microbial aggregation, shorten the formation time of granular sludge, and enhance the stability of the anaerobic system in general [5]. Chen et al. studied the impact of biocarbon on the performance of aerobic granulation and reactor during oil wastewater treatment. It was found that adding biocarbon can shorten the aerobic granulation time and increase the ability to resist the impact load [6]. Lei and $\mathrm{Xu}$ et al. using the activated carbon as the carrier of the UASB reactor, they found that activated carbon can shorten the starting time, increase methane production, and enhance the resistance of anaerobic granular sludge to organic load impact $[7,8]$. The above studies show that adding carrier material is an effective method to improve the performance of UASB reactor. It is also found that honeycomb stone can be used as artificial fillers for the treatment of sewage wastewater and carrier of microorganisms [9, 10], however, few studies use pumice as a carrier material for UASB reactors. As a natural green carrier, pumice displays excellent characteristics of high porosity, light weight, high strength, and corrosion resistance against acid and alkali [11]. Compared with other carrier materials, pumice has better microbial compatibility and economic and environmental protection. Thus, the objective of the present study is to determine whether the introduction of the pumice into the UASB reactor can improve the anti-impact load capability and shorter start-up times in leachate treatment. Particularly, our study uses the actual waste leachate as the treatment object, without artificial water distribution, which makes the experimental operation conditions more in line with the practical engineering applications.

\section{Material and Methods}

\section{Experimental Devices}

The experimental device (shown in Fig. 1) consisted of two plexiglass cylindrical UASB reactors $(4.5 \mathrm{~L}$ and $2 \mathrm{~L}$ ), a peristaltic pump, a heating rod and a circulating pump. Dimensions were 750, 89, and $110 \mathrm{~mm}$ in height, inner diameter, and outer diameter, respectively. The temperature was maintained at $35 \pm 1^{\circ} \mathrm{C}$ and controlled by the interlayer water bath present between the inner

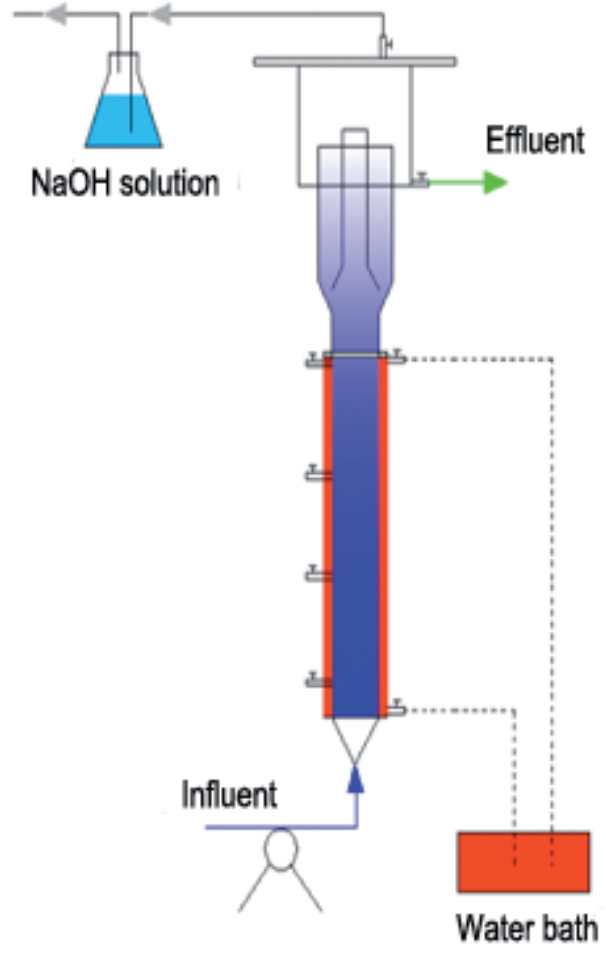

Fig. 1. Schematic diagram of the UASB reactors.

layer and outer layer of the reactor. The influent flow rate was controlled using a peristaltic pump. The reactor reaction area was wrapped with shading paper to avoid the influence of light on microorganisms.

\section{Inoculated Sludge and Fresh Leachate}

A reactor was used as an experimental control group (R1). The amount of inoculated sludge was about $30 \%$ of the effective volume of the reactor. The other reactor, $500 \mathrm{~g}$ pumice were added, and labeled as the experimental group (R2).

The sludge was collected from the sludge thickening tank of a landfill leachate power plant located in Anhui Province, China. The ratio of volatile (VSS) to total suspended solids (VSS/TSS) in the sludge was 0.57 . The fresh leachate was collected from the UASB anaerobic tank of the power plant as the feed water (shown in Table 1). The $\mathrm{pH}$ of the influent was adjusted at $7.0 \pm 0.3$ by adding sodium bicarbonate. The HRT (hydraulic retention time) was 15 hours during the whole operation.

\section{Analytical Methods}

The chemical oxygen demand (COD), TSS and VSS were measured according to the standard procedures [12]. DOMs concentrations of incoming and outgoing water samples were analyzed using a F-7000 fluorescence spectrophotometer (Hitachi, Japan). The excitation wavelength and emission wavelength range of the 3D fluorescence spectra were $200 \mathrm{~nm} \sim 450 \mathrm{~nm}$ and $280 \mathrm{~nm} \sim 550 \mathrm{~nm}$, respectively; the slit width was 
Table 1. The physicochemical parameters of leachate at MSW incineration plant located in Hefei, China.

\begin{tabular}{|c|c|}
\hline Parameters & MSW incineration leachate $(\mathrm{mg} / \mathrm{L})$ \\
\hline $\mathrm{COD}$ & $67445 \sim 71233$ \\
\hline $\mathrm{NH}_{3}-\mathrm{N}$ & $2970 \sim 3154$ \\
\hline $\mathrm{TN}$ & $3542 \sim 3820$ \\
\hline $\mathrm{TP}$ & $101 \sim 112$ \\
\hline $\mathrm{pH}$ & $5.2 \sim 6.5$ \\
\hline
\end{tabular}

set to $5 \mathrm{~nm}$, the scanning speed was $2400 \mathrm{~nm} / \mathrm{min}$ [13]. Because of the large fluorescence intensity of the diluted leachate, water samples were filtered with $0.45 \mathrm{~nm}$ filter membranes before analyses. In order to reduce the internal filtration effect produced by the fluorescence measurement, the filtered water samples were diluted. In order to eliminate the effect of Rayleigh scattering, a $290 \mathrm{~nm}$ cut-off filter was installed on the emitting fluorescence side. In addition, in order to eliminate the influence of Raman scattering, the MATLAB software was used to draw the $3 \mathrm{D}$ fluorescence spectrum map, and the ultrapure water blank data was subtracted from the water sample data [14].

\section{Microbial Community Analysis}

The sludge samples were collected from the control group reactor (R1) and the experimental group reactor (R2) at days 100 (stable stage) and 162 (strengthen stage), respectively. Microbial DNA extraction was carried out following the methods provided by the guidebook included in the soil DNA kit (purchased from Omega Bio-tek, Inc.) The quality of the extracted DNA was determined using $2 \%$ agarose gel electrophoresis. The $\mathrm{V} 3+\mathrm{V} 4$ regions of $16 \mathrm{~S}$ rRNA were amplified with the bacterial primers 338F: 5'-ACTCCTACGGGAGGCAGCA-3' and 806: 5'-GGACTACHVGGGTWTCTAAT-3'; for methanogen, MLf5'-GGTGGTGTMGGATTCACACA RTAYGCWACAGC and MLr5'-TTCATTGCRTAGT TWGGRTAGTT $[15,16]$. The amplicons were delivered to Illumina Miseq platform (Biomarker Technologies, Beijing) for high-throughput sequencing.

\section{Results and Discussion}

\section{Effect of Pumice on Impact Load Resistance}

As shown in Fig. 2, during the 168 days of anaerobic process in the UASB reactors, three stages are present: start-up stage, stable stage and strengthen stage. The COD concentrations of the influents are in the ranges of 950 2500, 2500 5000, and 5000 18000 ppm at the start-up, stable, and the strengthen stage, respectively. During the start-up stage, regardless pumice are present or not in the UASB reactors, the COD concentrations gradually increased from 950 to $2500 \mathrm{mg} / \mathrm{L}$. As the reactor continued continuously, the COD removal rates are stably over $85 \%$, R1 reaches stability at day 15 (pumice added), while R2 (control reactor) at day 27 .

At the stable stage, the COD influent loading maintains at medium level. In this case, the concentrations slowly increase from 2500 to $5000 \mathrm{mg} / \mathrm{L}$. This result indicates that both reactors can efficiently remove COD, and the COD removal efficiencies of those two reactor are both more than $90 \%$. With regards to stability, reactor R2 shows smaller fluctuations with the influent than R1.

Fig. 3 displays the detailed daily treatment capacity and COD removal efficiency of at the strengthen stage of the UASB reactors. When the organic loading rates increase from 13.85 to $33.28 \mathrm{~kg} \mathrm{COD} /\left(\mathrm{m}^{3} \cdot \mathrm{d}\right)$, the COD removal efficiencies in R1 and R2 decrease. With the increase of influent organic loads, the COD removal rate of the reactor R2 returns to $96 \%$ after 12 days and remained stable afterwards. These results further demonstrate that the addition of pumice a)

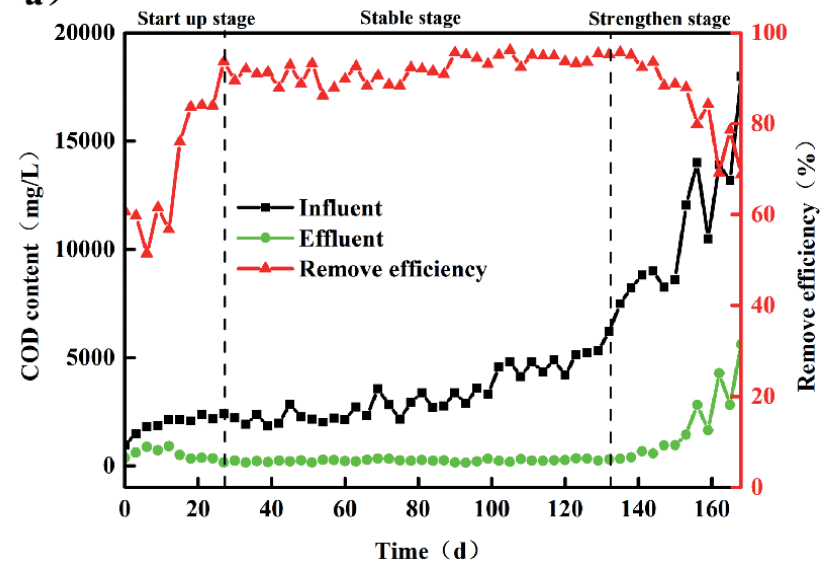

b)

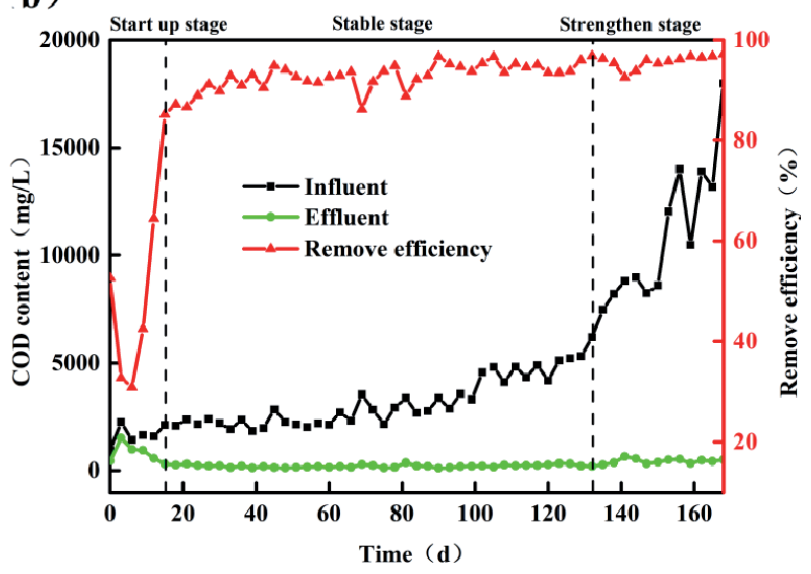

Fig. 2. The removal efficiencies of COD during different stages in R1 a) and R2 b) reactors. 
a)

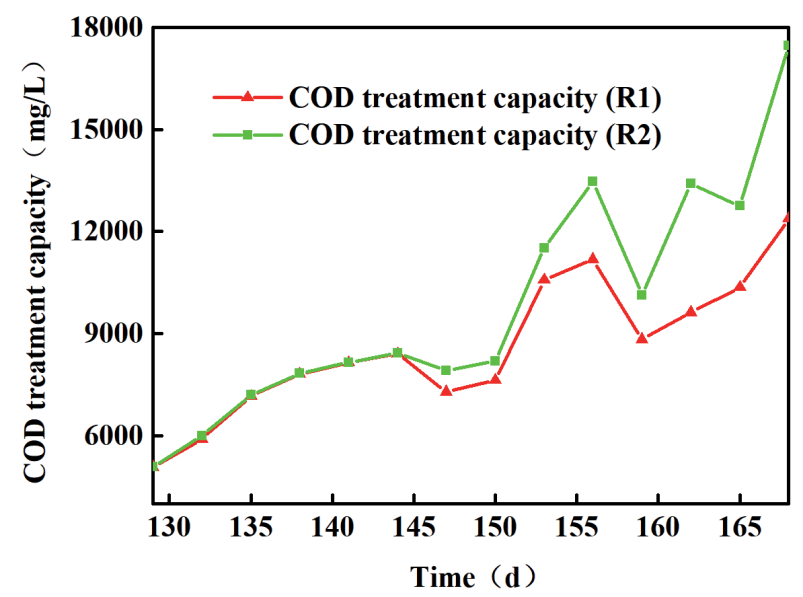

b)

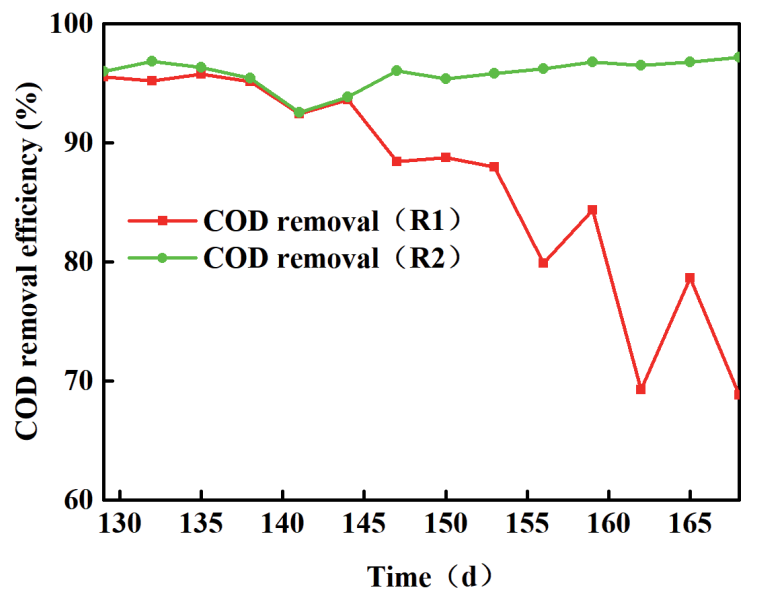

Fig. 3. a) The COD daily treatment capacity of R1 and R2 reactors at the strengthen stage, b) The COD removal rate of R1 and R2 reactors at the strengthen stage

is the UASB reactor effectively improves the performance during incineration leachate treatment, even when the OLR reached levels as high as $33.3 \mathrm{~kg}$ $\mathrm{COD} /\left(\mathrm{m}^{3} \cdot \mathrm{d}\right)$. In contrast, the COD removal efficiency in $\mathrm{R} 1$ is unstable, which decreases from $95.5 \%$ to $68.8 \%$ when OLR increased from $9.8 \mathrm{~kg} \mathrm{COD} /\left(\mathrm{m}^{3} \cdot \mathrm{d}\right)$ to $33.3 \mathrm{~kg}$ $\mathrm{COD} /\left(\mathrm{m}^{3} \cdot \mathrm{d}\right)$ (strengthen stage).

The addition of pumice enhanced COD removal as well as resistance to shock loadings. Furthermore, the start-up time of the UASB reactor is also reduced. Thus, the pumice contained reactor exhibits the best performance. The enhanced activities may be attributed to the development of a diverse microbial community. The high specific surface area and total pore volume of the pumice provide a good habitat for microorganisms. The presence of pumice help increasing microbial abundance, improve microbial activity, and promote the degradation of soluble organic matter.

\section{Three-Dimensional Fluorescence Analysis of Incoming and Outgoing Water}

EPS plays an important role in the physical and chemical properties of anaerobic granular sludge. SMP is composed of EPS hydrolysates and decay products of active cells, which are the main components of soluble organic matter in wastewater [17]. In the 3D-EEM spectra, five clear peaks can be observed. They are corresponding to five different components: (a) peak A, Ex/Em = 225/320 nm corresponds to the tyrosine protein; (b) peak B Ex/Em = 225/340 360 nm corresponds to tryptophan class proteins; (c) peak $\mathrm{C} \mathrm{Ex} / \mathrm{Em}=280 / 350(305) \mathrm{nm}$ indicates the soluble microbial metabolites; (d) peak D Ex/Em = 330/410(415) $\mathrm{nm}$ indicates the presence of humic acid substances; and peak $\mathrm{E} E x / E m=250 / 450(455) \mathrm{nm}$ corresponded to ferric acid [18]. Fig. 4 shows the changes of the fluorescence peaks of the landfill leachate before and after treatment with the UASB reactor. After treatment, the fluorescence intensity $\mathrm{A}, \mathrm{B}$, and $\mathrm{C}$ significantly decrease, and the absorption peak which correspond to tyrosine protein-related substances disappear. This result indicates the presence of fulvic acids in the effluent. It is likely that these fulvic acids were produced by microbial metabolism [19]. Comparing these results to that of control (R1), the peak intensities of $\mathrm{B}, \mathrm{C}, \mathrm{D}$, and $\mathrm{E}$ in $\mathrm{R} 2$ are $10.5 \%, 14.8 \%, 9.9 \%$, and $22.9 \%$ lower, respectively. These results indicate that the addition of pumice improves the degradation of soluble organic matter and promoted the metabolism of microorganisms. However, pumice does not have significant effect on SPM components.

\section{Bacterial Community Diversity Analysis}

Sludge samples from Day 100 (R1(100) and $\mathrm{R} 2(100))$ and day 162 (R1(168) and R2(168)) were sequenced using the Illumina Miseq platform. The alpha diversity indexes are displayed in Table 2. In all samples, coverage are higher than $99 \%$, indicate that the sequencing results represent the real composition of the samples [20]. The presence of pumices in the reactor significantly increases the Shannon index on the days of 100 and 162. In contrast, Simpson diversity is significantly reducing in the presence of pumice on the days of 100 and 162 . At the same time, the Chao index and the ACE index increase, indicating that the pumice positively affects the development and richness of bacterial diversity.

Fig. 5 displays the results of the statistical analysis based on OTUs (operational taxonomic units). As the results shown, a total of 551 OTUs are obtained on day 100 after sequencing. In addition, 501 species are present in all samples, and the species unique to R1 and R2 are 17 and 33, respectively. Moreover, on day 162, total OTUs increases, and the number of 
a)

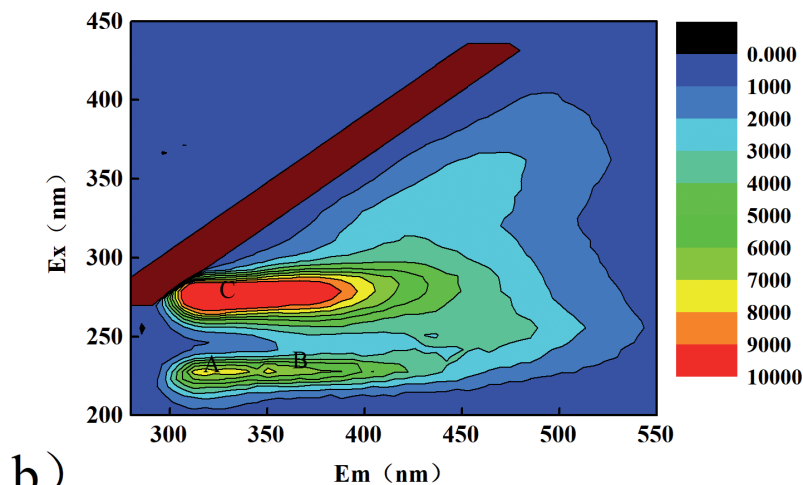

b)
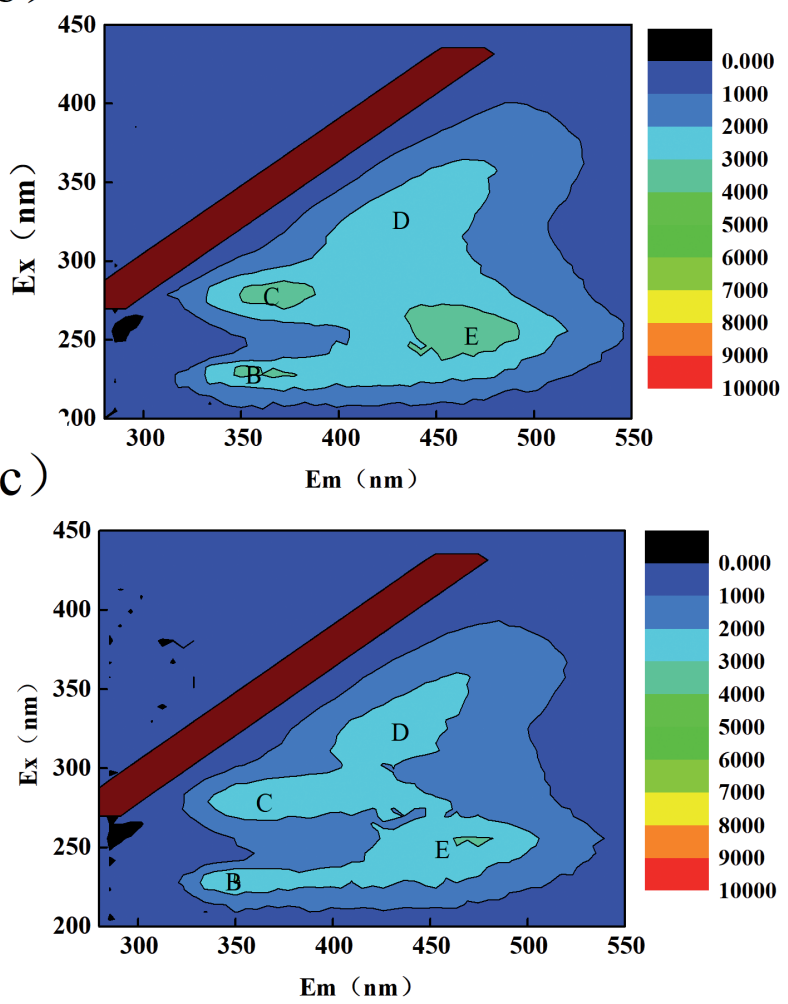

Fig. 4. a) The three-dimensional fluorescence spectra of R1 and $\mathrm{R} 2$ reactor influent water at the strengthen stage, b) and c) The three-dimensional fluorescence spectra of R1 and R2 reactor effluent water at the strengthen stage, respectively.

endemic species in R1 and R2 increases to 43 and 71, respectively. At the same stage, the number of OTUs endemic species in reactor R2 is higher than that in reactor R1. All these data suggest that the addition of pumice increases the species and number of bacterial OTUs. In consequence, these materials may favor the degradation of some characteristic pollutants.

\section{Changes in Microbial Community Structure}

Fig. 6 presents the distribution of bacteria at the phylum, class, and genus levels in the anaerobic granular sludge. According to the results (Fig. 6a), in both reactors, the dominant phyla in the granular sludge are Firmicutes, Proteobacteria, Bacteroidetes, Chloroflexi, and Synergistetes. Thus, the presence of pumice does not affect the number of species; however, they affect their abundance. On days 100 and 162, the relative abundance of Proteobacteria and Chloroflexi in the R2 reactor are always higher than that in R1. Proteobacteria are able to degrade complex macromolecular organic matter and long-chain VFAs [21]. Chloroflexi are usually found in the anaerobic digestion system. These fermentative bacteria produce hydrolases that are able to degrade soluble microbial products, including soluble proteins and soluble polysaccharides [22]. Other studies have shown that Chloroflexi displays the ability to transfer extracellular electrons to electron receptors, which can promote DIET, improving the anaerobic digestion efficiency of reactors [23]. Moreover, after organic load, the relative abundance of Firmicutes in the R2 reactor increases from $27.7 \%$ to $49.0 \%$, while that in R1 is relatively stable. Firmicutes are widely found in the anaerobic digestive system. They always contain endospores that resist harsh environments and are the main bacteria responsible for removing COD [24].

At the class level (Fig. 6b), it is found that different reactors displayed different proportions of dominant species (Fig. 5b). On days 100 and 162, the predominant microbes are Clostridia, Bacteroidia, Deltaproteobacteria, and Anaerolineae. After the organic influent loaded, the relative abundance of Clostridia in the R2 reactor increases from $23.1 \%$ to $40.3 \%$. However, the increase is relatively small in the $\mathrm{R} 1$ reactor. Clostridia are strictly anaerobic bacteria that produce butyric acid and acetic acid by decomposing carbohydrates [25]. This process promotes the growth of related acid-type methanogens and improves the degradation efficiency of organic matter.

At the genus level (Fig. 6c), Syntrophomonas accounted for $2.47 \%, 2.21 \%, 3.29 \%$, and $3.91 \%$ of R1(100), R2(100), R1(162), R2(162) total bacterial genera, respectively. As members of specialized

Table 2. On days 100 and 162, the alpha diversity index of bacterial community in sludge of R1 and R2 reactors.

\begin{tabular}{|c|c|c|c|c|c|c|c|c|}
\hline Type of strain & Stage & Sample & OTU & ACE & Chao1 & Simpson & Shannon & Coverage \\
\hline \multirow{4}{*}{ Bacteria } & \multirow{3}{*}{ Stable stage } & R1(100) & 518 & 529.7151 & 532.5882 & 0.0486 & 4.1772 & 0.9993 \\
\cline { 3 - 10 } & & R2(100) & 534 & 536.2273 & 539.0770 & 0.0180 & 4.8000 & 0.9997 \\
\cline { 2 - 10 } & \multirow{2}{*}{ Strengthen stage } & R1(162) & 508 & 524.9262 & 536.8889 & 0.0238 & 4.6216 & 0.9992 \\
\cline { 3 - 10 } & & R2(162) & 536 & 543.1494 & 545.7308 & 0.0209 & 4.7303 & 0.9996 \\
\hline
\end{tabular}


a)

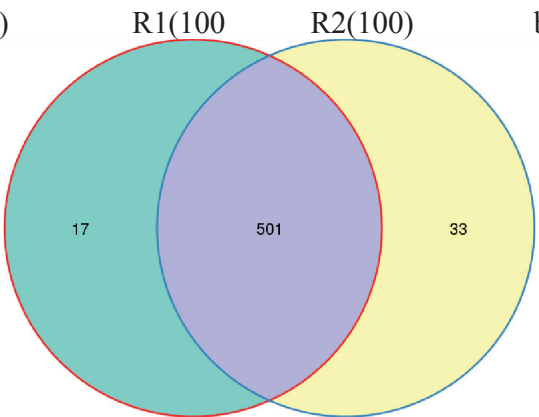

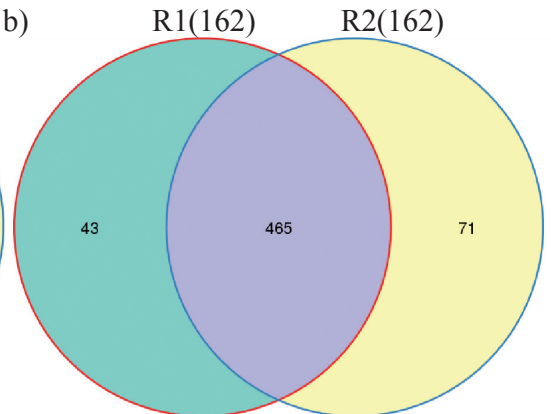

Fig. 5. On days 100 and 162, the quantity of OTU with $97 \%$ similarity in anaerobic granular sludge of R1 and R2 reactors.

a)

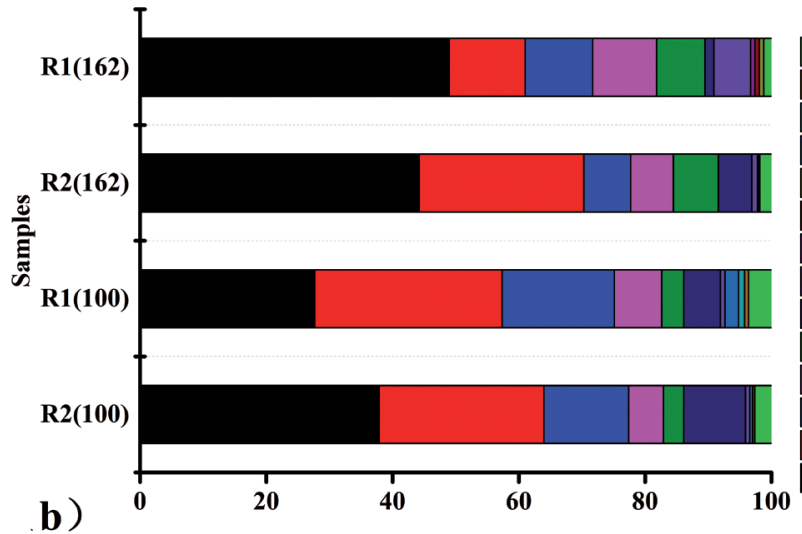

Others

Aegiribacteria

Deinococcus-Thermus

Spirochaetes

WPS-2

Armatimonadetes

Acidobacteria

Actinobacteria

Patescibacteria

Synergistetes

Chloroflexi

Proteobacteria

Bacteroidetes

Firmicutes

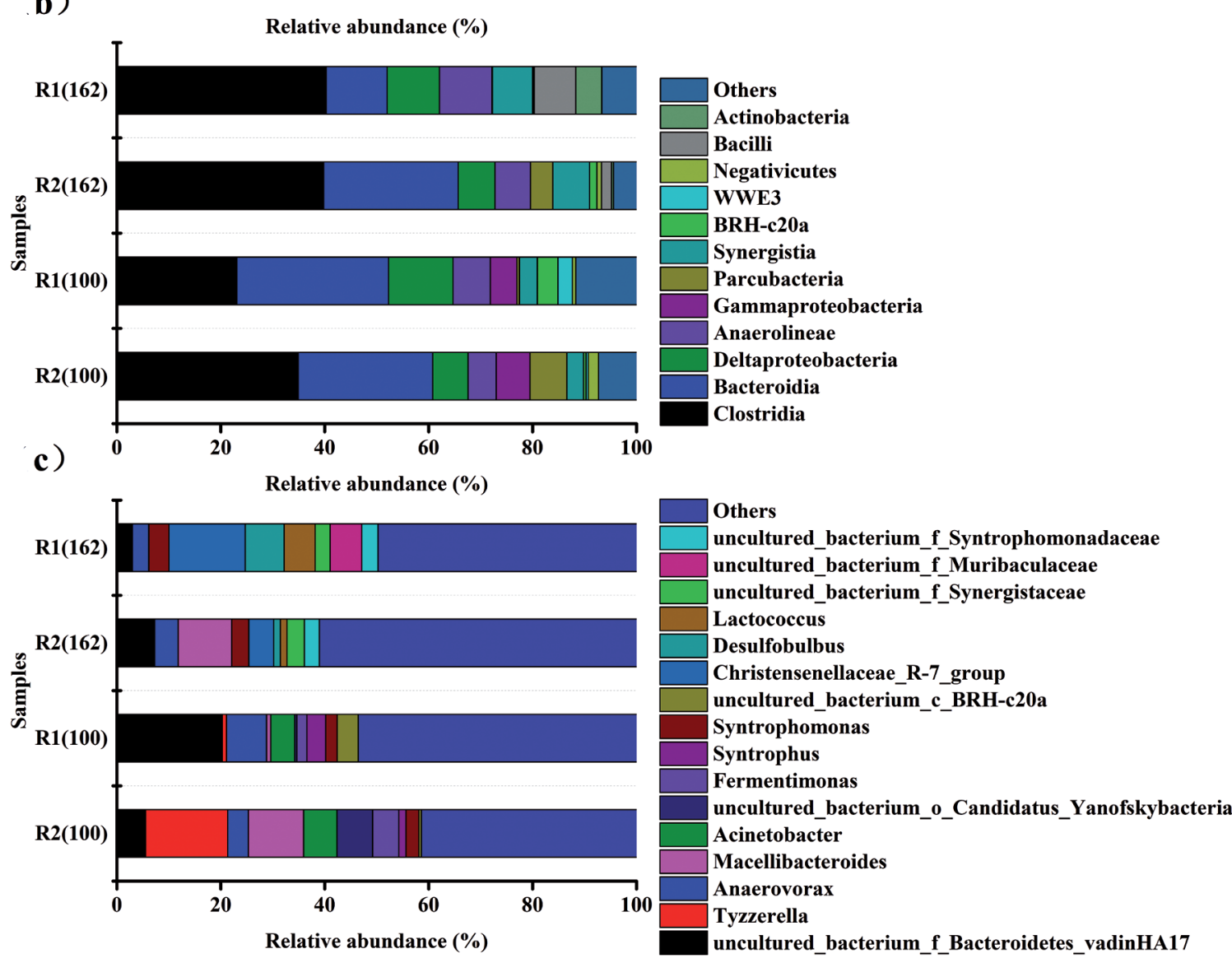

Fig. 6. On days 100 and 162, the bacteria community structure in anaerobic granular sludge of R1 and R2 reactors, a) phylum level; b) class level; and c) genus level. "Others" represents all classified taxa that were $<0.1 \%$ in all samples. 


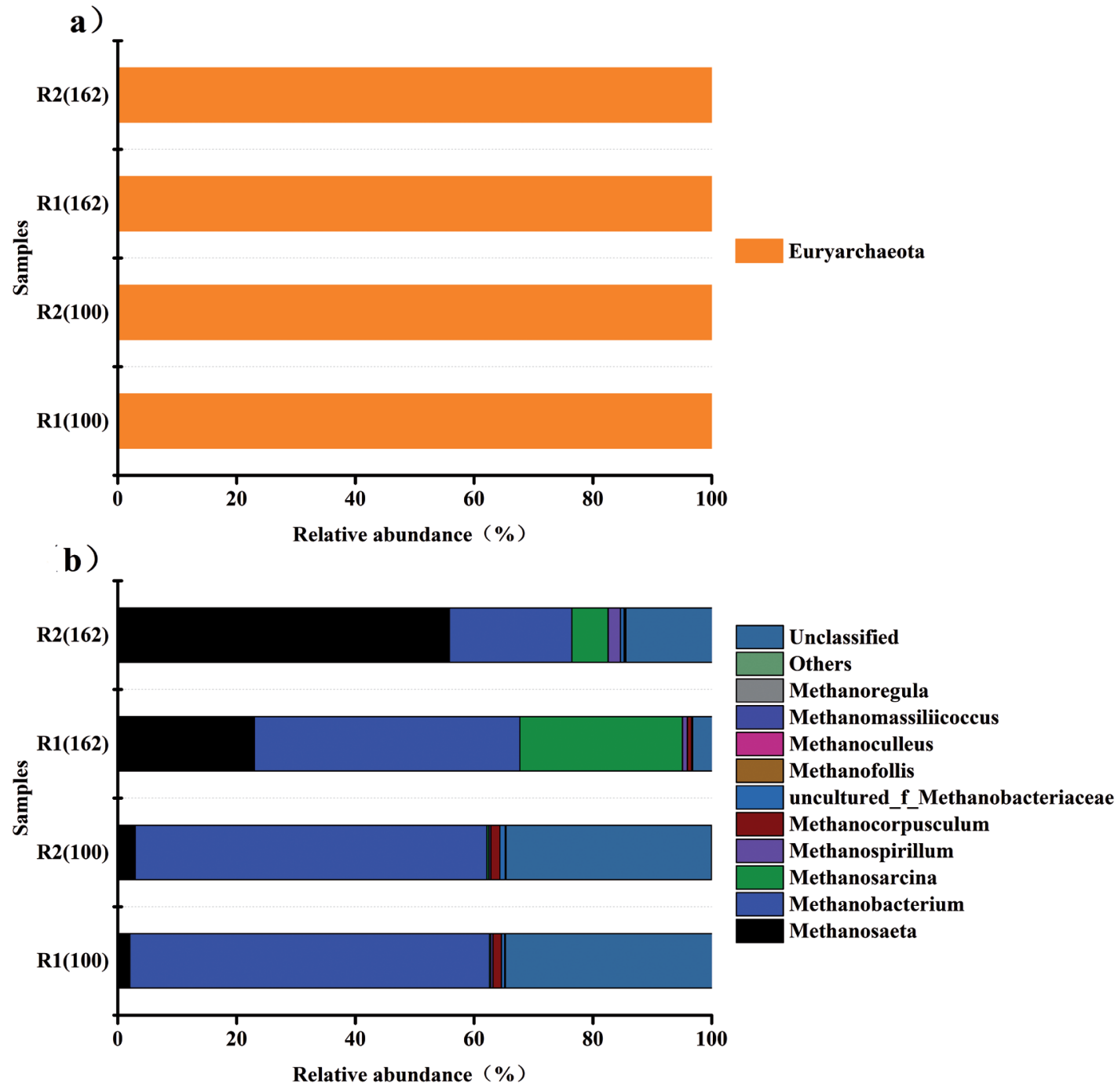

Fig. 7. On days 100 and 162, methanogens community structure in anaerobic granular sludge of R1 and R2 reactors, a) phylum level and b) genus level. "Others" represents all classified taxa that were $<0.1 \%$ in all samples.

anaerobic and cocultured bacteria, Syntrophomonas possesses the ability to oxidize butyrate and other VFAs into acetic acid. They are usually present during hydrogen synthesis in combination with methanogens and other hydrogen-using microorganisms. Their presence in the system, although not very abundant at the onset stage, is likely to induce functional microbial growth and promote digestion processes [26].

\section{Changes in Community Structure of Methanogens}

As known, methane is produced during the anaerobic degradation of organic matter. Methane production is considered to be the action of related methanogens [27]. At the phylum level, microbial community structure showed that Euryarchaeota is the dominant species in R1 and R2. On day 100, the dominant methanogens in R1 and R2 are both Methanobacterium, and their relative abundances account for $60.55 \%$ and $59.23 \%$ of the total methanogen sequence, respectively. In addition, Methanosaeta account for only $2.01 \%$ and $2.91 \%$, correspondingly. On day 162 , the relative abundance of Methanobacterium in R1 and R2 decrease to $44.71 \%$ and $20.59 \%$, respectively. On the other hand, Methanosaeta relative abundance increase to $22.98 \%$ and $55.86 \%$, correspondingly. The abundance of dominant methanogens also changed.

Methanobacterium are the hydrogen-type methanogenic bacteria present during the anaerobic treatment of organic matter. They use $\mathrm{H}_{2} / \mathrm{CO}_{2}$ or formic acid to produce methane [28]. Also, Methanosaeta are strict anaerobes, which not only use acetic acid as substrate to produce methane, but also reduce carbon dioxide to methane by the effect of DIET receiving Electrons [29]. Methanosarcina are also acidtype methanogens; however, unlike Methanosaeta, they tolerate high salinity and high acetic acid concentrations [30]. With the increase of organic load, Methanobacterium in both reactors show different 
degrees of inhibition, which promoted the growth of Methanosaeta. The increase in the relative abundance of Methanosaeta in the $\mathrm{R} 2$ reactor is 2.6 times higher than that in R1. It is likely that pumices improved the acid buffer capacity of the anaerobic system and maintained a relatively stable environment for the microorganisms. The acid accumulation in the control group increase slowly, inhibiting the growth rate of Methanosaeta and stimulating the growth of the acid-resistant bacteria Methanosarcina.

\section{Conclusions}

The addition of pumice during anaerobic processes represents a feasible technology to improve pollutant removal and anti-shock loading. Even when the organic loading rates increased to $33.28 \mathrm{~kg}$ $\mathrm{COD} /\left(\mathrm{m}^{3} \cdot \mathrm{d}\right)$, the COD removal efficiency remains stable at $>90 \%$. However, the maximum organic loading rates of the reactor without pumice is only $13.85 \mathrm{~kg}$ $\mathrm{COD} /\left(\mathrm{m}^{3} \cdot \mathrm{d}\right)$. Further investigation of the microbial community indicates that pumice can increase the bacterial abundance and diversity, promote the growth of Proteobacteria and Chloroflexi. With the increase of organic loading rates, pumice are favorable for the growth of Methanosaeta and enhanced the UASB acid buffer capacity. These results verify the effectiveness of the application of pumice in UASB reactors and provide a good theoretical basis for the treatment of landfill leachate.

\section{Acknowledgments}

This work is supported by the National Key Research and Development Program (2019YFC0408504), the Science and Technology Service Network Initiative of the Chinese Academy of Sciences (KFJ-STSQYZD-173), the Major Natural Science Projects in Universities of Anhui Province (KJ2018ZD048),

\section{Conflict of Interest}

The authors declare that they have no known competing financial interests or personal relationships that could have appeared to influence the work reported in this paper.

\section{References}

1. YANG Y. Design of Leachate Treatment in a Domestic Waste Incineration Power Plant. Chemical Enterprise Management, 21 (10), 195, 2019.

2. LIU J.W., KANG X.Y., YUE P., CHEN X.W., TIAN H.Y. Project Design of Total Quantitative Treatment of Leachate of Urban Municipal Waste Comprehensive Treatment Plant. China Water \& Wastewater, 36 (10), 70, 2020.
3. YIN X. Composition on Main System of Domestic Waste Incineration Power Plant. Jilin Electric Power, 48 (1), 40, 2020.

4. LIU F. Study on the development and performance of anaerobic granular sludge. Xi'an University of Technology, 2019.

5. MA J.Y., WANG B.H., QIAO Z.R., XIE B. Effects of carbon-based materials on anaerobic digestion efficiency and microbial community of food waste. Chinese Journal of Applied \& Environmental Biology, 26 (3), 730, 2020.

6. MING J., WANG Q.H., YOZA B.A., LIANG J.H., GUO H.Q., LI J., GUO S.H., CHEN C.M. Bioreactor performance using biochar and its effect on aerobic granulation. Bioresource Technol, 300 (5), 122620, 2020.

7. LEI Y.Q., SUN D.Z., DANG Y., FENG X.L., HUO D., LIU C.Q., ZHENG K., DAWN E.H. Metagenomic analysis reveals that activated carbon aids anaerobic digestion of raw incineration leachate by promoting direct interspecies electron transfer. Water Research, 161 (2), 570, 2019.

8. XU S.Y., HE C.Q., LUO L.W., LV F., HE P.J., CUI L.F. Comparing activated carbon of different particle sizes on enhancing methane generation in up-flow anaerobic digester. Bioresource Technology, 196 (2), 606, 2015.

9. LI X.B., DENG R.Y., ZHANG Y. Experimental research on modification of pumice and its adsorption performance to $\mathrm{Mn}^{2+}$. Industrial Water \& Wastewater, 48 (3), 21, 2017.

10. LU Y.F., MA L.J., MA L., SHAN B., CHANG J.J. Improvement of start-up and nitrogen removal of the anammox process in reactors inoculated with conventional activated sludge using biofilm carrier materials. Environmental technology, 39 (1), 59, 2018.

11. ZHANG Y. Research on the habitat improvement and ecological reconstruction in urban malodorous river: technique coupling effect and its mechanism. East China Normal University, 2010.

12. C.E.P.B. Standard Methods for Water and Wastewater Analysis, $4^{\text {th }}$ ed.; China Environmental Science Press: Beijing, China, 67-69, 2002.

13. LI H.Q., LIU X.Y., SUN Y., CAI X.B., LI J.Y. Characteristic analysis of organic matter through treatment processes of leachate in a MSW incineration plant. Environmental Science \& Technology, 43 (07), 154, 2020.

14. WANG R., YAO L., SHEN H.Y., YU L., LI W.H. Characterizing the effect of $\mathrm{Fe}(\mathrm{II})$ dosage on anammox treatment process using excitation-emission matrix fluorescence spectroscopy and parallel factor analysis. Journal of Environmental Engineering Technology, 9 (6), 658,2019

15. SONG J.Y., QIN R., DU X.Y., WU H.J., LIANG L.B. Study on Microbial Diversity and Metabolic Function in the Point Source Wastewater Treatment System of Oil Refinery. Res of Environmental Sciences, 2021.

16. SONG Y.J., MENG S.Y., CHEN G.Y., YAN B.B., ZHANG Y.X., TAO J.Y., LI Y.H., LI J.L. Co-digestion of garden waste, food waste, and tofu residue: Effects of mixing ratio on methane production and microbial community structure. Journal of Environmental Chemical Engineering, 9 (5), 105901, 2021.

17. WANG X.H., ZHU M.H., LI F.F., ZHANG C.X., ZHU X.B. Long-term effects of multi-walled carbon nanotubes on the performance and microbial community structures of an anaerobic granular sludge system. Applied Microbiology and Biotechnology, 102 (21), 9351, 2018.

18. JIE Z., JUN-JIAN W., ANTOINE B., ALEX T.C. Improved Fluorescence Excitation-Emission Matrix Regional Integration to Quantify Spectra for Fluorescent 
Dissolved Organic Matter. J Environmental Qual, 42 (3), 925, 2013.

19. LASPIDOU C.S., RITTMANN B.E. A unified theory for extracellular polymeric substances, soluble microbial products, and active and inert biomass. Water Research, 36 (11), 2711, 2002.

20. GENG S.Y., FU W.Z., WANG J., ZHENG S.L. Treatment Efficiency and Microbial Community Diversity in a Magnetic Field Enhanced Sequencing Batch Reactor (SBR). Environmental Science, 38 (11), 4715, 2017.

21. WANG C.Q., LIU Y., JIN S., CHEN H., XU X.Y., WANG Z.R., XING B., ZHU L. Responsiveness extracellular electron transfer (EET) enhancement of anaerobic digestion system during start-up and starvation recovery stages via magnetite addition. Bioresource Technology, 272 (8), 162, 2019.

22. CHEN Y.W., YANG Z.H., ZHANG Y.R., XIANG Y.P., XU R., JIA M.Y., CAO J., XIONG W.P. Effects of different conductive nanomaterials on anaerobic digestion process and microbial community of sludge. Bioresource Technol, 304 (3), 123016, 2020.

23. XIA Y., WANG Y.B., WANG Y., CHIN F., ZHANG T. Cellular adhesiveness and cellulolytic capacity in anaerolineae revealed by omics-based genome interpretation. Biotechnology Biofuels, 9 (1), 111, 2016.

24. ZHANG Z., GAO P., CHENG J., LIU G., ZHANG X., FENG Y. Enhancing anaerobic digestion and methane production of tetracycline wastewater in EGSB reactor with GAC/NZVI mediator. Water Research, 136 (5), 54, 2018.

25. SU C., LIN X., ZHENG P., CHEN Y., ZHAO L., LIAO

Y., LIU J. Effect of cephalexin after heterogeneous
Fenton-like pretreatment on the performance of anaerobic granular sludge and activated sludge. Chemosphere, 235 (4), 84, 2019

26. XING B., HAN Y., WANG X.C., MA J., CAO S., LI Q., WEN J., YUAN H. Cow manure as additive to a DMBR for stable and high-rate digestion of food waste: Performance and microbial community. Water Research, 168 (5), 115099, 2020.

27. JIANG J., WANG Y., LIU J., YANG X., REN Y., MIAO H., PAN Y., LV J., YAN G., DING L., LI Y. Exploring the mechanisms of organic matter degradation and methane emission during sewage sludge composting with added vesuvianite: Insights into the prediction of microbial metabolic function and enzymatic activity. Bioresource Technology, 286 (2), 121397, 2019.

28. LI Z.H., HU Y.Y., LIU C.Y., SHEN J., WU J., HUAIZHI LI H.Z., KAIJUN K.J., ZUO J. Performance and microbial community of an expanded granular sludge bed reactor in the treatment of cephalosporin wastewater. Bioresource Technology, 275 (6), 94, 2019.

29. YANG B., XU H., LIU Y., LI F., SONG X., WANG Z., SAND W. Role of GAC-MnO ${ }^{2}$ catalyst for triggering the extracellular electron transfer and boosting $\mathrm{CH}_{4}$ production in syntrophic methanogenesis. Chemical Engineering Journal, 383 (1), 123211, 2020.

30. LIAO Y.Q., JAEHAC K., YUAN T.G., XU Q.Y. Effect of sewage sludge derived biochar addition on methane production and microbial community structure of anaerobic digestion on food waste. Journal of Environmental Engineering, 14 (2), 523, 2020. 
